\title{
Management of cull dairy cows: Culling decisions, duration of transport, and effect on cow condition
}

\author{
J. Stojkov, ${ }^{1 *}$ * M. A. G. von Keyserlingk, ${ }^{1} \odot$ T. Duffield, ${ }^{2}{ }^{\oplus}$ and D. Fraser ${ }^{1}$ \\ ${ }^{1}$ Animal Welfare Program, Faculty of Land and Food Systems, The University of British Columbia, Vancouver, V6T 1Z4, Canada \\ ${ }^{2}$ Ontario Veterinary College, University of Guelph, ON, N1G 2W1, Canada
}

\begin{abstract}
Many cows culled from dairy farms arrive at livestock markets or abattoirs in compromised condition, but it is unknown whether cows are compromised at the time of culling or deteriorate during the marketing process. This study followed cull cows from farm to abattoir, monitored any deterioration, and tested the effect of providing such information on subsequent culling. For 11 mo, data were collected from 20 dairy farms, livestock markets, and abattoirs. Cows' body condition, lameness, and udder condition (as binary outcomes) were assessed at 4 points: when placed on the culling list, before leaving the farm, at auction, and at the abattoir. Based on the first 5 mo of data (baseline period), information materials were provided to 10 randomly selected farms (Informed treatment), and the other 10 served as a Control. Logistic mixed models were used to test differences in cows' condition at the 4 points of assessment, using the assessment before leaving the farm as a reference value and cow-within-farm as a random effect. The effects of providing information on outcome measures (proportion thin, severely lame, with udder edema, poor fitness for transport, euthanized, and died) were tested with a general linear model. As demand for milk increased during the baseline period, additional linear mixed models were fitted to test whether the same outcome measures were affected by time (baseline or treatment period) and treatment (Informed or Control) using farm as a random effect. While cows were on the culling list (before shipping) the odds of being thin or having poor fitness for transport increased. After leaving the farms, cows spent (mean \pm standard deviation) $82 \pm 46 \mathrm{~h}$ in the marketing system before being slaughtered. Shipping from farm to abattoir increased the odds of being thin, having udder edema, or showing poor fitness for transport [odds ratio (OR)
\end{abstract}

Received August 9, 2019.

Accepted November 18, 2019.

*Corresponding author: j.stojkov@alumni.ubc.ca
5.8, 95\% confidence interval 4.2 to 8.1 ; OR $14.7,10.7$ to 20.2 ; and OR 7.3, 5.7 to 9.5, respectively]. Providing this information to farmers (Informed treatment) did not affect the outcome measures. Compared with the baseline, during the treatment period fewer cows were shipped when thin (4.9 versus $9.0 \%$ ) and with poor fitness for transport (15.7 versus $25.8 \%$ ), and fewer cows died (5.4 versus $11.9 \%$ ) or were euthanized (13.3 versus $20.5 \%$ ). Increased demand for milk appeared to lead to delayed culling, such that more compromised cows were sent to slaughter. The results of this study show a need for clear and specific guidelines to assess fitness for transport of cull dairy cows.

Key words: dairy cow, culling decision, fitness for transport, slaughter

\section{INTRODUCTION}

Managing dairy herds requires continuous replacement of less-productive cows with younger, more productive, and genetically superior replacement heifers. In this dynamic herd management process, farm managers gather and process diverse information and make regular culling decisions. Farm managers have different management styles, perceive risks and benefits of factors differently, and handle information differently; some consider longevity and genetic selection as a priority, whereas others seek mostly to maintain milk production (Beaudeau et al., 1996). Regardless of management style, farmers consider many individual cow factors, such as milk production, fertility, SCC, foot problems, and other factors, before reaching a culling decision (Beaudeau et al., 2000). Moreover, external factors such as demand for milk, milk price, feed price, and cost and availability of replacement heifers can also influence culling decisions (Hadley et al., 2006).

At the time of culling, cows typically have 1 or more health conditions that are often cited as the specific reason for removal. In 2018, the 5 most cited reasons for removing cows from Canadian dairy farms included reproductive problems (17\%), mastitis (11\%), foot and leg problems (7\%), low milk production $(8 \%)$, and sick- 
ness (4\%; CDIC, 2019). Thus, although some cows are removed because of low fertility or low milk production, many are ill, and some likely experience pain, as from lameness or mastitis (Whay et al., 1998; Fitzpatrick et al., 2013; Evans et al., 2016), and these conditions reduce their ability to withstand transport (González et al., 2012b).

The marketing of culled cows commonly includes handling and transport to livestock markets and then to abattoirs. This final leg of the journey has been reported as relatively short; for example, mean transport duration was $4.6 \mathrm{~h}$ in Ontario (Warren et al., 2010a) and $6.7 \mathrm{~h}$ in the United States (Harris et al., 2017). However, long-distance journeys of more than 1,000 km and lasting for $16 \mathrm{~h}$ are not uncommon (González et al., 2012a). Regardless of transport duration, many compromised cows have been observed at livestock markets (Ahola et al., 2011; Moorman et al., 2018) and abattoirs in Canada and the United States (Van Donkersgoed et al., 2001; Harris et al., 2017).

Cull dairy cows are a vulnerable category of animals that can develop lameness, become non-ambulatory, or die when subjected to long-duration transport (González et al., 2012b). Even with shorter transport $(\sim 3 \mathrm{~h})$ they can acquire wounds, develop engorged udder, and experience increased lameness (Dahl-Pedersen et al., 2018). In countries such as Canada and the United States, where abattoirs are widely dispersed and tend to be selective about the types of cattle they slaughter, long-duration transport $(>400 \mathrm{~km})$ and delays to slaughter (7 to $10 \mathrm{~d}$ ) occur regularly (González et al., 2012a; Stojkov et al., 2018; Edwards-Callaway et al., 2019). Moreover, the current transport regulations in Canada allow cattle, including lactating cows, to be continuously transported for $48 \mathrm{~h}$ without feed and water, although cows in heavy lactation must be milked at 12-h intervals (CARC, 2001).

Collectively, these studies suggest that some cows removed from dairy farms have a variety of health problems, and a portion of cull dairy cows arrive at auctions and abattoirs with compromised health. However, whether cows develop these negative welfare states at the farm of origin, during transport, or in the marketing system remains unknown. Moreover, many farmers and veterinarians are not aware of the delays that commonly occur from farm to slaughter (Stojkov et al., 2018) and hence do not take the likely delays into account when deciding to ship animals. This study was designed to gather information about the duration of travel from farm to abattoir and to evaluate any changes in the condition of cull dairy cows. The study also tested whether providing information to farmers about common delays to slaughter would influence their subsequent decisions to ship cull dairy cows.

\section{MATERIALS AND METHODS}

This study was approved by the University of British Columbia Animal Care Committee (\#A16-0336) and the Behavioral Research Ethics Board (\#H17-00009). Participating farms provided written consent, and the livestock markets and abattoirs provided verbal agreement. Participation of all parties was entirely voluntary.

\section{Participants and Data Collection}

The study monitored the condition of cull dairy cows at 3 locations: (1) on 20 commercial dairy farms in the Fraser Valley, British Columbia (BC), Canada (the largest dairy region in $\mathrm{BC}),(2)$ at 2 livestock markets in $\mathrm{BC}$, where many of the cows were sold, and (3) at 6 abattoirs in BC, Alberta, and Washington state (USA), where many were slaughtered.

Participating dairy farms were recruited by invitations facilitated through local veterinary practices and 2 producer associations. Livestock markets and abattoirs were invited to participate through their associations. Farms and livestock markets participated throughout the study, whereas abattoirs entered the study at different times depending on the managers' decision to participate. One local abattoir stopped slaughtering cattle during the study, reducing the number of participating abattoirs from 6 to 5 .

During data collection (May 2017 to March 2018) the primary observer was in regular (weekly) communication with participating farms via telephone and visited on the days when farmers made their culling decisions. Cows included in the study were assessed for locomotion, body condition, and udder condition. Locomotion was assessed using a 5-point locomotion score (LS; Flower and Weary, 2006), where $1=$ sound and $5=$ severely lame. Body condition was evaluated using a chart of BCS for Holstein dairy cows (1 to 5 scale, 0.5 increments), where 1 was severe underconditioning (emaciated) and 5 was severe overconditioning (Edmonson et al., 1989; Ferguson et al., 1994). Udder condition was scored using a 3 -point scale, where $1=$ normal milked (loose) udder, 2 = tight or engorged udder, and $3=$ swollen or inflamed udder. Cow parity (lactation number) was recorded as $1,2,3$, or $\geq 4$, and DIM as 1 to 100, 101 to 200, 201 to 305, and >305 DIM.

A composite measure of fitness for transport was created for each cow, following industry standards (NFACC, 2009; DFC-PLC, 2017; CFIA, 2019). Specifically, cows were scored as 1 (poor fitness for transport) if they had one or more of the following conditions: $\mathrm{BCS} \leq 2, \mathrm{LS} \geq 4$, or udder condition $\geq 2$; all others were scored as 0 (good fitness for transport). 
At the participating farms, 2 groups of cows were identified: those designated to be removed from the breeding herd (placed on the culling list), and those designated for immediate shipping to auction or slaughter (shipping list). Cows already on the culling list when the study began were assessed immediately. All new cows added to the culling list were assessed when the decision was made; this was weekly, biweekly, or monthly, based on the farm dynamic. Cows were assessed again when placed on the shipping list, 1 to 3 $\mathrm{d}$ before they were shipped from the farm. These cows were marked with a distinct mark using cattle spray (Tell Tail Aerosol, FIL Industries, Tauranga, New Zealand) to make them easy to recognize at auctions and abattoirs. Assessors at the abattoirs were informed about the impending arrival of study cows and were asked to watch for the cows on arrival.

Cows at the farms and livestock markets were assessed by 1 primary observer (a veterinarian) and 2 trained auxiliary observers (1 government dairy inspector and 1 veterinarian). The primary observer assessed more than $90 \%$ of the cows at the farms and livestock markets, with the auxiliary observers involved periodically. After initial training, the interobserver reliability of the primary observer and the dairy inspector was tested regularly. Intraobserver reliability was tested every 3 mo for the primary observer and on 2 occasions (midway and at the end of the study) for the dairy inspector. Because the other auxiliary observer joined later, interobserver reliability was tested twice (midway and at the end of the study), and intraobserver reliability was tested at the end of the study.

Cows arriving at the participating abattoirs were assessed on arrival, in the holding pen, or when walking to the slaughter line, by abattoir inspectors ( 3 veterinarians and 3 meat inspectors) who had been trained to use the scoring systems. The initial training was scheduled after each abattoir agreed to participate in the study and based on the inspectors' availability. Evaluation of the observers' scoring skills was scheduled to occur approximately every $3 \mathrm{mo}$, based on observers' availability and work schedules. Because each observer's length of involvement in the study varied, observers had 1 to 3 interobserver reliability tests and 1 (4 observers) or no (2 observers) intraobserver reliability tests midway or at the end of the study. Testing involved a combination of live observations, photos, and videos. To estimate the total duration of transport, the inspectors also recorded the time and date when the cows arrived and were slaughtered; the proportion of total time in transport that was spent at the international border was not recorded. Inspectors' involvement in the study was voluntary; 1 inspector dropped out during the study because of work-related restrictions.
Because excellent agreement between observers $\left(\mathrm{K}_{\mathrm{w}}\right.$ $>0.80$ ) was not always achieved, each outcome measure (BCS, LS, udder condition) was expressed as a binary variable: 1 if cows were thin $(\mathrm{BCS} \leq 2)$, if cows were severely lame ( $\mathrm{LS} \geq 4$ ), or if the udder showed engorgement or inflammation (udder condition $\geq 2$ ); 0 otherwise. This approach was taken under the assumption that consistent detection of extreme conditions could be achieved more easily.

During the study, 815 cows were assessed when placed on the culling list, and 1,171 cows were assessed when removed from participating farms. These 1,171 animals included cows from the culling list (531) and cows that were removed directly from the herd without being placed on the culling list (640). Of the cows removed, 615 were reassessed at the livestock markets, and 12 of these $(2 \%)$ were observed at 2 different livestock markets, apparently because they were resold. Observers recorded 731 of the cows at participating abattoirs, of which 518 were assessed after the initial training of the inspectors was completed (Figure 1). For 538 cows, the observers recorded the time when the animal was slaughtered, and this time was used to calculate the time elapsed from farm to slaughtering (Figure 2). One cow arrived at the abattoir dead, and 2 were nonambulatory at arrival and had to be euthanized.

A power calculation test, "Difference between two independent proportions" (G*Power Version 3.1.9.4, Universität Kiel, Kiel, Germany), was used to calculate the sample size needed per group to detect a 10\% differ-

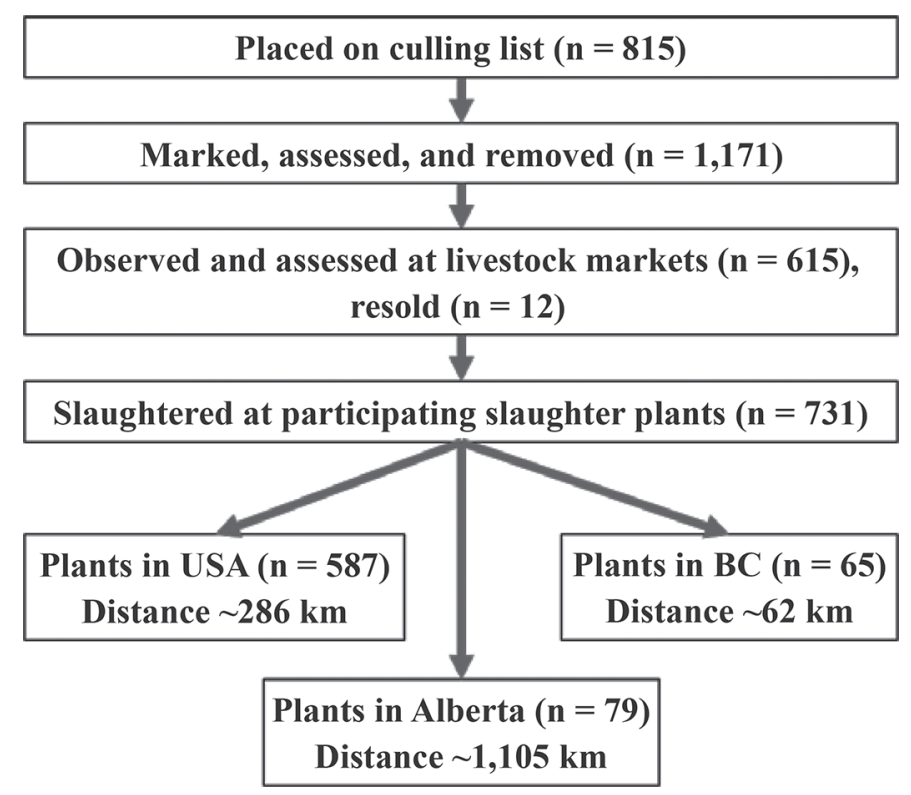

Figure 1. Movement of cull dairy cows (with number of animals) from 20 participating farms located in the lower Fraser Valley region of British Columbia (BC), Canada, to livestock markets and abattoirs. 


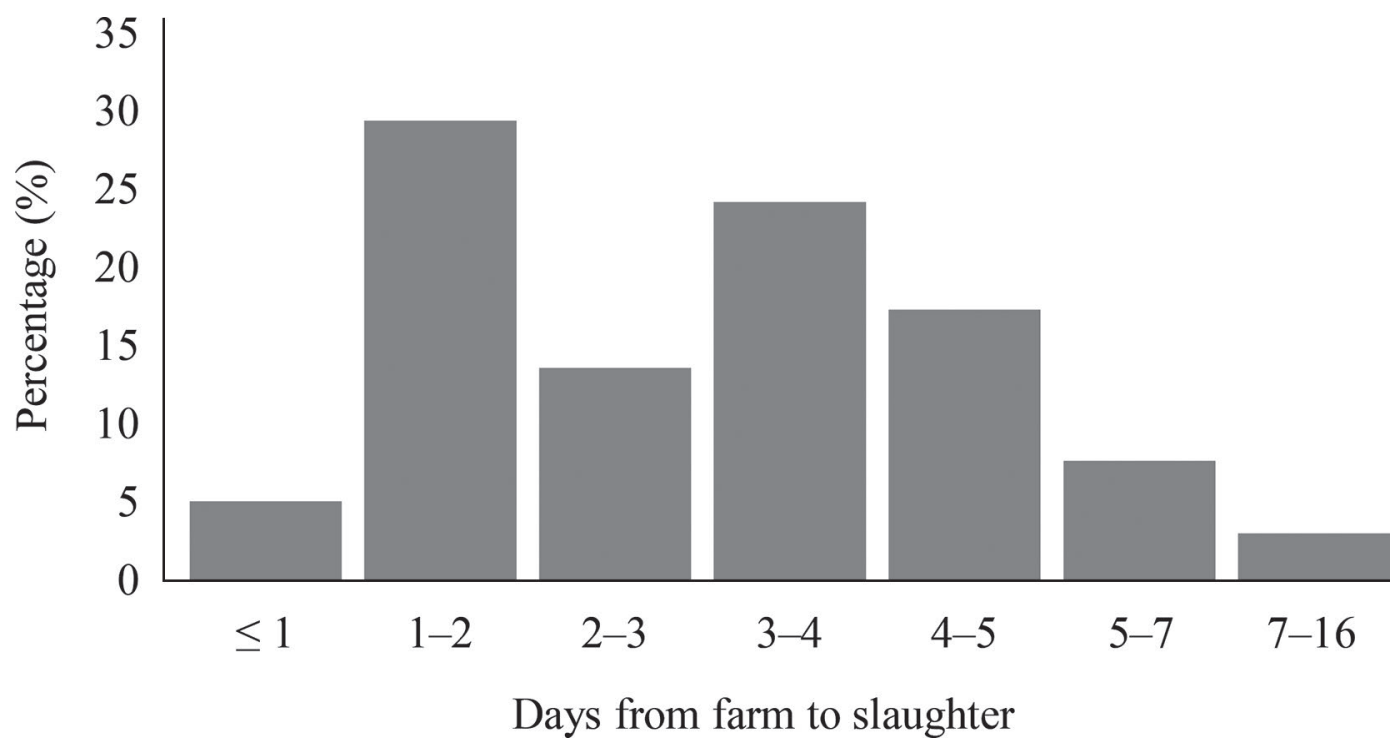

Figure 2. Percentage of cows that underwent different delays (in days) from the 20 farms of origin until slaughter, including the time cows spent at livestock markets, assembly yards, and abattoir yards. Data were gathered for 538 cull dairy cows.

ence between 2 proportions: thin cows $(\mathrm{BCS} \leq 2)$ at the farm of origin (35\%) and at the abattoir $(45 \%)$, with $\alpha$ $=0.05$ and power of 0.80 . Two tests were conducted: (1) considering equal population ratio between farm and abattoir, which required 376 cows per group or, in total, 752 cows, and (2) considering unequal population ratio between farm and abattoir, with farm having twice as many cows as the abattoir, which required 560 cows at the farm and 280 cows at the abattoir or, in total, 840 cows. This sample size calculation is a conservative estimate, because this test considers cows as independent observations, whereas cows were clustered by farm in the study design.

\section{Testing the Effects of Providing Information}

Based on data gathered from May to September 2017 , informational materials were provided to half of the participating farms (Informed treatment) during November 2017; the other farms constituted the Control treatment. To allocate farms to treatment, farms were first assigned to pairs of farms with similar herd size and served by the same veterinary clinic where possible; then 1 farm in each pair was randomly assigned to each treatment. Owners or farm managers in the Informed treatment were provided with information on the findings of the first months of the study, including duration of transport, conditions of cull cows at auction and at the abattoir, and prices paid at the auction markets, plus a simplified decision-tree tool for deciding whether to load a cow for transport. This tool was developed following industry standards (NFACC, 2009) and described actions appropriate for different conditions observed in dairy cows. It specified (1) that cows should not be transported if they are non-ambulatory, thin $(\mathrm{BCS} \leq 2)$, or severely lame $(\mathrm{LS}=5)$, or show signs of weakness, fever, or clinical mastitis; (2) that cows should be transported with special provisions (direct to slaughter) if they are lame $(\mathrm{LS}=4)$, in heavy lactation, or in early stages of pneumonia, or if they show displaced abomasum, are blind, or had calved within 48 $\mathrm{h}$; (3) that the herd veterinarian should be consulted if farmers are uncertain about a cow's fitness for transport; and (4) that on-farm emergency slaughter be considered, where legal, for cows with an acute injury. These producers were also given the contact number of a veterinarian for free telephone consultation and the contact number of a local abattoir manager if they wished to ship cows directly to the abattoir (direct-toslaughter). These information meetings lasted about 30 min and were delivered by a veterinarian (the auxiliary observer). Producers in the Control treatment were not provided with this information. The researcher who carried out the regular on-farm assessments remained blind to the treatment assignment. The goal was to test whether providing such information would influence farmers' culling decisions.

The effect of the treatment was tested by comparing the condition of animals at the time of shipping and the frequency of using alternative options (euthanasia, direct-to-slaughter, emergency slaughter) for removing compromised cows. These measures were gathered for each farm before (baseline period) and after the intervention (treatment period), and included the number of 
cows scored as thin $(\mathrm{BCS} \leq 2)$ or severely lame $(\mathrm{LS} \geq$ 4 ), cows with udder condition $\geq 2$, and cows with poor fitness for transport, expressed as count data or as a proportion of the total cows shipped. Because few cows were removed from the farms using alternative options, these variables were not used in the analysis. In addition, data were gathered on the number of cows that died or were euthanized and the total number removed from the herd.

\section{Statistical Analyses}

Microsoft Access Database (Microsoft Office 2016, Microsoft Corp., Redmond, WA) was used to calculate the time cows spent in the marketing system. All statistical analysis was completed in SAS (version 9.4, SAS Institute Inc., Cary, NC).

Intra- and interobserver reliability for BCS, LS, and udder condition were evaluated using unweighted kappa coefficients (K). Prevalence index (PI) and bias index (BI) were calculated to measure the effect that prevalence of the observed conditions and observer bias had on the reliability coefficients (Sim and Wright, 2005).

Generalized linear mixed-effects models (Proc Glimmix) were used to determine any deterioration in the condition of the cows between the 4 points of assessment: (1) when placed on the culling list, (2) when placed on the shipping list, (3) at auction, and (4) at the abattoir. The distribution was set as binary to fit the binary outcome variables, with logit link and residual pseudo-likelihood estimation. To account for variation due to individual cows and farm of origin, cow-withinfarm was set as a random effect. Parity and DIM were included as covariates. A separate model was used to evaluate deterioration of each outcome variable: BCS, LS, udder condition, and fitness for transport. In each model, a reference value for each explanatory variable was selected. Specifically, category 1 to 100 DIM was used as reference value for DIM, parity $\geq 4$ for parity, and scores when cows were placed on the shipping list as reference values for point of assessment. Udder condition at the first point of assessment (i.e., culling list) was not included in the analysis because cows at this stage were regularly milked and treated for mastitis if necessary. Because observations were missing at different points of assessment, 2 data sets were created and tested with these models. The first included all observations, and the second excluded all animals with missing observations. The analyses showed the same findings, and thus we used the larger data set for the final analysis. The similarity of the results from the 2 data sets likely reflects the robustness of the mixedeffect models, even when used with unbalanced and missing data.
The effect of the intervention on the outcome measures (the count of cows that were thin, were severely lame, had an engorged or inflamed udder, or had poor fitness for transport) was tested using negative binomial regression, where the baseline period was used as a covariate and the number of cows shipped to auction (observed by the researcher) as an offset variable. The same model was used to test the effect of the intervention on the number of cows that died or were euthanized on the farm, using the total number of cows removed as an offset variable. The models were constructed using the Genmod procedure in SAS, with the response distribution set as negative binomial with $\log$ link function. To test whether the veterinary clinic $(n=4)$ influenced the outcome measures of the intervention, the veterinary clinic that served the farms was also included as a covariate in the model. Because the models for the outcome variables BCS, fitness for transport, died, and euthanized did not converge, the outcome measures from count data were transformed to percentages. For example, the number of thin cows sent to auction was expressed as a percentage of total cows sent to auction, and cows that died or were euthanized was expressed as a percentage of total cows removed from the herd. A general linear model (Proc GLM) was applied to these percentages to test the effect of the intervention, using separate models for each outcome measure and including the veterinary clinic and the baseline period as covariates.

Exploratory analysis, using the same outcome measures used to test the intervention, was performed to test the differences between the baseline and treatment periods. This analysis was done because demand for milk (a requirement for each farm to increase production as set by the provincial Milk Marketing Board) increased during all months of the baseline period (May to Nov.) but not during the treatment period (Dec. to Mar.), except for the month of December. Time (baseline period or treatment period), treatment (Informed or Control), and interaction between time and treatment were used as explanatory variables, and the veterinary clinic was added as a covariate. Because the interaction was not significant, it was removed from all final models. Initially all models were fitted with negative binomial regression, with farm as a random effect, but the models did not converge except for the number that died or were euthanized. To fit linear mixed-effects models, the outcome variables were transformed from count data to percentage that were thin, were severely lame, had an engorged or inflamed udder, and had poor fitness for transport, and cows that died or were euthanized (as described above). After this transformation, all models converged except the model for udder condition. After running diagnostic tests for this model, 
it was confirmed that the random effect was interfering with the model; hence the random effect was removed, and a linear model without random effect was fitted. Results from the exploratory analysis that had $P>$ 0.05 are also reported.

\section{RESULTS}

Herd size (mean \pm SD) of participating farms at the beginning of the study, including milking and dry cows, was $311 \pm 255$ cows. Most of the study cows were Holstein $(99.3 \%)$, with a few Jersey or Jersey $\times$ Holstein cross $(0.7 \%)$. Cows were removed from the herd at a mean $( \pm \mathrm{SD})$ parity of $2.9 \pm 1.6$ and BCS of $3.1 \pm 0.7$ (Appendix Table A1). Cows were placed on the culling list at (mean \pm SD) $209 \pm 126$ DIM, were removed from the farm at $273 \pm 184 \mathrm{DIM}$, and spent $127 \pm 112$ $\mathrm{d}$ on the culling list before being removed from farms. About $80 \%$ were slaughtered at abattoirs in the United States and were transported (mean \pm SD) $286 \pm 220$ $\mathrm{km}$. Cows slaughtered at plants in Alberta (11\%) were transported 1,105 $\pm 190 \mathrm{~km}$, and those slaughtered in the local plants in British Columbia (9\%) were transported $62 \pm 4 \mathrm{~km}$ (Figure 1). After leaving the farms, cows spent (mean $\pm \mathrm{SD}) 82 \pm 46 \mathrm{~h}$ in the marketing system. When they reached the slaughter plant, BCS was reduced to $2.7 \pm 0.6$. Including delays at auctions or assembly yards, 27 cows (5\%) were slaughtered within $1 \mathrm{~d}$ after being removed from the farm, $43 \%$ within 2 to $3 \mathrm{~d}, 41 \%$ in 4 to $5 \mathrm{~d}$, and $8 \%$ in 5 to $7 \mathrm{~d}$, and 16 cows $(3 \%)$ spent 8 to $16 \mathrm{~d}$ in the marketing system (Figure 2).

Unweighted kappa coefficients for intra- and interobserver agreement for the 9 assessors who contributed to the final data set indicated moderate to excellent agreement, which ranged from 0.48 to 1.00 and 0.45 to 1.00, respectively, for BCS, 0.69 to 1.00 and 0.52 to 1.00 for lameness score, and 0.79 to 1.00 and 0.49 to 1.00 for udder condition score. The prevalence index ranged from 0.03 to 0.95 , and the bias index ranged from 0.00 to 0.18 (Appendix Table A2). The bias index was used to detect observers' "drift," which was not observed in this study (Sim and Wright, 2005).

\section{Changes in Condition from Farm to Abattoir}

Compared with the time of shipping (used as a reference value), when cows were first placed on the culling list they had lower odds of being thin, but the odds of being thin increased when arriving at the abattoir (Table 1; overall model: $F_{3,1316}=48.12, P<0.0001$ ). Cows in early lactation (0 to 305 DIM) had higher odds of losing body condition than those in late lactation (DIM $\left.>305 ; F_{3,1316}=21.42, P<0.0001\right)$. Older cows ( $\geq$ 3rd parity) had higher odds of having reduced body condition at abattoirs than did cows in parity 1 or 2 (Table $1 ; F_{3,1316}=3.31, P=0.02$ ).

Severe lameness (Table 2) did not change while cows were on the culling list, at shipping, or on arrival at the abattoir, but cows at auction showed reduced odds of being scored as severely lame (overall model: $F_{3,1188}=$ 6.91, $P<0.001)$. Stage of lactation did not influence locomotion score, but higher parity ( $\geq 2$ nd parity) was associated with increased odds for developing severe lameness (Table $2 ; F_{3,1188}=8.56, P<0.0001$ ).

Udder condition (Table 3) did not deteriorate from the time of shipping until cows were scored at auction, but cows arriving at abattoirs had greater odds of acute

Table 1. Results of logistic mixed-effects regression indicating how the odds of low BCS (BCS $\leq 2)$ varied depending on different assessment points, DIM, and parity; data were gathered from 20 participating dairy farms by assessing all removed cull dairy cows ${ }^{1}$

\begin{tabular}{|c|c|c|c|c|c|}
\hline Effect & Estimate & $\mathrm{SE}$ & $t$-value & $P$-value & $\begin{array}{c}\text { Odds ratio } \\
(95 \% \text { confidence limits })\end{array}$ \\
\hline Intercept & -4.062 & 0.260 & -15.65 & $<0.0001$ & - \\
\hline \multicolumn{6}{|l|}{ Assessment point } \\
\hline Placed on shipping list (referent) & - & - & - & - & - \\
\hline At auction & -0.026 & 0.210 & -0.12 & 0.901 & $0.97(0.65-1.47)$ \\
\hline At abattoir & 1.760 & 0.170 & 10.34 & $<0.0001$ & $5.81(4.16-8.12)$ \\
\hline $101-200$ & 1.679 & 0.237 & 7.1 & $<0.0001$ & $5.36(3.37-8.53)$ \\
\hline 201-305 & 0.904 & 0.246 & 3.67 & 0.0003 & $2.47(1.52-4.01)$ \\
\hline$>305$ (referent) & - & - & - & - & - \\
\hline \multicolumn{6}{|l|}{ Parity } \\
\hline First (referent) & - & - & - & - & - \\
\hline Second & 0.128 & 0.267 & 0.48 & 0.6314 & $1.14(0.67-1.92)$ \\
\hline Third & 0.511 & 0.256 & 1.99 & 0.0463 & $1.67(1.01-2.75)$ \\
\hline
\end{tabular}

${ }^{1}$ Number of cows is reported in the Materials and Methods section. 
Table 2. Results of logistic mixed-effects regression indicating how the odds of severe lameness [locomotion score (LS) $\geq 4$ ] varied depending on different assessment points, DIM, and parity; data were gathered from 20 participating dairy farms by assessing all removed cull dairy cows ${ }^{1}$

\begin{tabular}{|c|c|c|c|c|c|}
\hline Effect & Estimate & $\mathrm{SE}$ & $t$-value & $P$-value & $\begin{array}{c}\text { Odds ratio } \\
\text { (95\% confidence limits) }\end{array}$ \\
\hline Intercept & -3.217 & 0.271 & -11.88 & $<0.0001$ & - \\
\hline \multicolumn{6}{|l|}{ Assessment point } \\
\hline Placed on shipping list (referent) & - & - & - & - & - \\
\hline At auction & -0.999 & 0.234 & -4.26 & $<0.0001$ & $0.37(0.23-0.58)$ \\
\hline At abattoir & -0.074 & 0.212 & -0.35 & 0.7281 & $0.93(0.61-1.41)$ \\
\hline $101-200$ & 0.071 & 0.233 & 0.3 & 0.7622 & $1.07(0.68-1.70)$ \\
\hline $201-305$ & -0.190 & 0.236 & -0.8 & 0.4213 & $0.83(0.52-1.31)$ \\
\hline$>305$ (referent) & - & - & - & - & - \\
\hline \multicolumn{6}{|l|}{ Parity } \\
\hline First (referent) & - & - & - & - & - \\
\hline Second & 0.856 & 0.305 & 2.81 & 0.0051 & $2.35(1.29-4.28)$ \\
\hline Third & 0.980 & 0.306 & 3.2 & 0.0014 & $2.67(1.46-4.86)$ \\
\hline
\end{tabular}

${ }^{1}$ Number of cows is reported in the Materials and Methods section.

milk accumulation or inflammation (overall model: $\left.\mathrm{F}_{2,1025}=169.76, P<0.0001\right)$. Cows in earlier stages of lactation $(\mathrm{DIM} \leq 305)$ and older cows $(\geq 3$ rd parity) had higher odds of developing signs of udder engorgement and inflammation (Table $3 ; F_{3,1025}=19.54, P<$ 0.0001 , and $F_{3,1025}=5.19, P<0.01$, respectively).

When placed on the culling list, cows had lower odds of poor fitness for transport than at the time of shipping (Table 4). Similarly, cows at auction had lower odds of poor fitness for transport, mostly because of lower lameness scores, as discussed below. However, cows arriving at the abattoir had much greater odds of poor fitness for transport (overall model: $F_{3,1318}=106.38, P$ $<0.0001)$. Compared with cows in late lactation $(>305$
DIM), high odds of poor fitness for transport were observed in every earlier stage of lactation, particularly cows in the first $100 \operatorname{DIM}\left(F_{3,1318}=25.86, P<0.0001\right)$. Multiparous cows had higher chances of having poor fitness for transport; this was especially true of cows of $\geq 4$ th parity (Table $4 ; F_{3,1318}=12.93, P<0.0001$ ).

\section{Effect of Providing Information}

The experimental intervention (i.e., provision of information to half of the participants) did not improve the condition of cows removed. However, the exploratory analysis indicated improved outcomes during the treatment period compared with the baseline period,

Table 3. Results of logistic mixed-effects regression indicating how the odds of udder engorgement and inflammation (udder condition $\geq 2$ ) varied depending on different assessment points, DIM, and parity; data were gathered from 20 participating dairy farms by assessing all cull dairy cows ${ }^{1}$

\begin{tabular}{|c|c|c|c|c|c|}
\hline Effect & Estimate & $\mathrm{SE}$ & $t$-value & $P$-value & $\begin{array}{c}\text { Odds ratio } \\
\text { (95\% confidence limits) }\end{array}$ \\
\hline Intercept & -3.633 & 0.221 & -16.44 & $<0.0001$ & - \\
\hline \multicolumn{6}{|l|}{ Assessment point ${ }^{2}$} \\
\hline At auction & -0.086 & 0.208 & -0.42 & 0.6776 & $0.92(0.61-1.38)$ \\
\hline At abattoir & 2.687 & 0.163 & 16.51 & $<0.0001$ & $14.69(10.68-20.22)$ \\
\hline \multicolumn{6}{|l|}{ DIM } \\
\hline$>305$ (referent) & - & - & - & - & - \\
\hline \multicolumn{6}{|l|}{ Parity } \\
\hline First (referent) & - & - & - & - & - \\
\hline Second & 0.140 & 0.232 & 0.6 & 0.5457 & $1.15(0.73-1.81)$ \\
\hline Third & 0.673 & 0.223 & 3.02 & 0.0026 & $1.96(1.27-3.04)$ \\
\hline$>$ Fourth & 0.661 & 0.210 & 3.14 & 0.0017 & $1.94(1.28-2.93)$ \\
\hline
\end{tabular}

${ }^{1}$ Number of cows is reported in the Materials and Methods section.

${ }^{2}$ The assessment point "culling list" was omitted in this analysis, as explained in the Statistical Analyses section. 
Table 4. Results of logistic mixed-effects regression indicating how the odds of poor fitness for transport (fitness score of 1) varied depending on different assessment points, DIM, and parity; data were gathered from 20 participating dairy farms by assessing all removed cull dairy cows 1

\begin{tabular}{|c|c|c|c|c|c|}
\hline Effect & Estimate & $\mathrm{SE}$ & $t$-value & $P$-value & $\begin{array}{c}\text { Odds ratio } \\
(95 \% \text { confidence limits })\end{array}$ \\
\hline Intercept & -2.622 & 0.169 & -15.48 & $<0.0001$ & - \\
\hline \multicolumn{6}{|l|}{ Assessment point } \\
\hline Placed on culling list & -0.714 & 0.219 & -3.26 & 0.0011 & $0.49(0.32-0.75)$ \\
\hline Placed on shipping list (referent) & - & - & - & - & - \\
\hline At auction & -0.383 & 0.143 & -2.68 & 0.0075 & $0.68(0.52-0.90)$ \\
\hline At abattoir & 1.989 & 0.131 & 15.17 & $<0.0001$ & $7.31(5.65-9.45)$ \\
\hline $101-200$ & 1.034 & 0.165 & 6.27 & $<0.0001$ & $2.81(2.04-3.89)$ \\
\hline $201-305$ & 0.548 & 0.163 & 3.36 & 0.0008 & $1.73(1.26-2.38)$ \\
\hline$>305$ (referent) & - & - & - & - & - \\
\hline \multicolumn{6}{|l|}{ Parity } \\
\hline First (referent) & - & - & - & - & - \\
\hline Second & 0.442 & 0.184 & 2.4 & 0.0164 & $1.56(1.09-2.23)$ \\
\hline Third & 0.763 & 0.184 & 4.16 & $<0.0001$ & $2.15(1.50-3.08)$ \\
\hline
\end{tabular}

${ }^{1}$ Number of cows is reported in the Materials and Methods section. Poor fitness for transport was considered when a cow had 1 or more of the following conditions: $\mathrm{BCS} \leq 2$, locomotion score $\geq 4$, or udder condition $\geq 2$.

regardless of treatment. Specifically the percentage of thin cows $(\mathrm{BCS} \leq 2)$ sent to auction declined from 9.0 $\pm 1.5 \%$ in the baseline period (May to Nov.) to $4.9 \pm$ $1.5 \%$ in the treatment period (Dec. to Mar.; $F_{1,19}=$ 7.13, $P=0.02$; Figure 3). Moreover, the percentage of thin cows sent to auction varied depending on the veterinary clinic that serviced the farm $\left(F_{1,19}=7.06, P\right.$ $=0.05 ;$ Figure 4$)$.

The percentage of severely lame cows sent to auction was also lower in the treatment period $(7.8 \pm 2.1 \%)$ than in the baseline $\left(10.8 \pm 2.1 \% ; F_{1,19}=1.92, P=\right.$
0.18 ) and lower on the farms serviced by a certain veterinary clinic $\left(F_{3,19}=1.94, P=0.16\right)$, but the percentage of severely lame cows removed from the farms was not influenced by treatment.

The percentage of cows with udder edema sent to auction declined from $9.4 \pm 2.3 \%$ in the baseline period to $4.9 \pm 2.3 \%$ in the treatment period $\left(F_{1,19}=2.69, P\right.$ $=0.11$ ), but neither the treatment nor the veterinary clinic showed any influence on this outcome variable.

The percentage of cows with poor fitness for transport declined from $25.8 \pm 3.1 \%$ in the baseline period

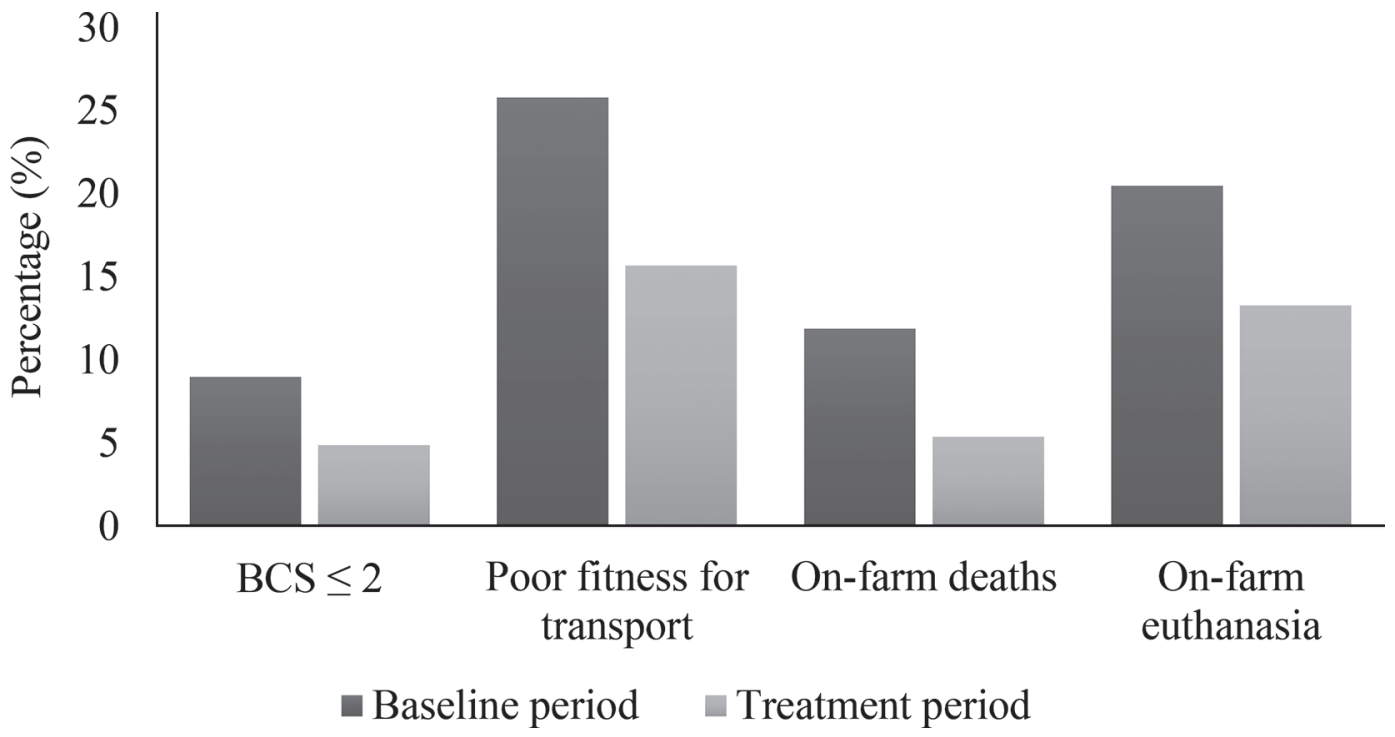

Figure 3. Percentage of thin cows and cows with poor fitness for transport sent to auction, and cows that died or were euthanized on farm, during the baseline and treatment periods. Data were gathered from 20 participating Canadian dairy farms by assessing all removed cull dairy cows. 


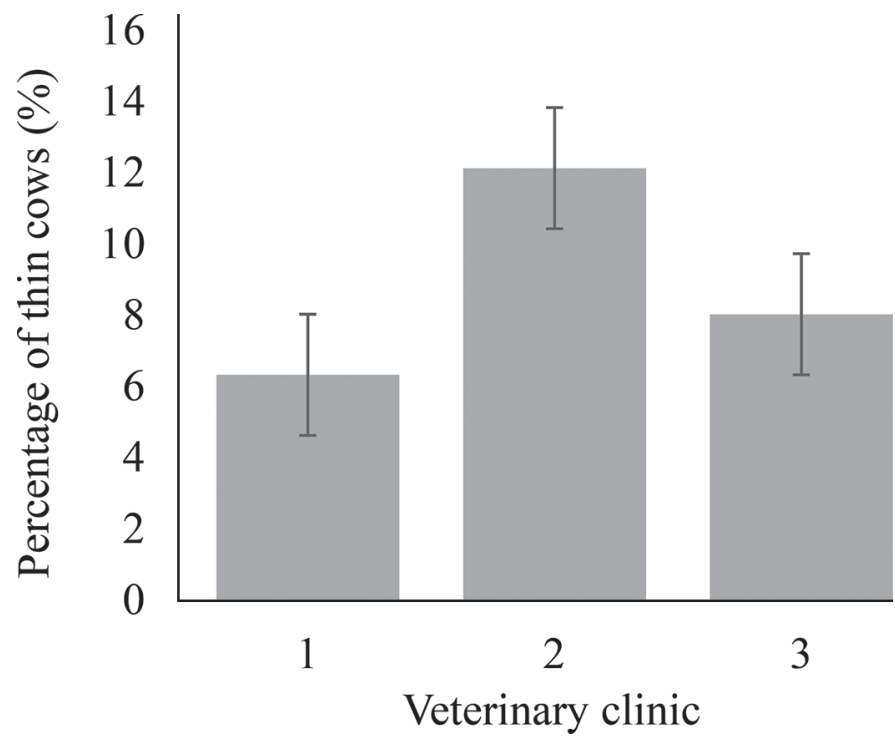

Figure 4. Percentage of thin cows (mean \pm SE) sent to auction from 19 farms in Canada that received services from 3 different veterinary clinics. One farm that received services from a fourth clinic was omitted.

to $15.7 \pm 3.1 \%$ during the treatment period $\left(F_{1,19}=\right.$ 9.92, $P<0.01)$. Treatment did not influence fitness for transport, but again clients of certain veterinary clinics shipped fewer cows with poor fitness for transport $\left(F_{3,19}\right.$ $=1.89, P=0.17)$.

The percentage of cows that died (expressed as a percentage of total cows removed from the herd) declined from $11.9 \pm 2.4 \%$ in the baseline period to $5.4 \pm 2.4 \%$ during the treatment period $\left(F_{1,19}=12.41, P<0.01\right)$. The percentage of euthanized cows also declined from $20.5 \pm 3.0 \%$ in the baseline period to $13.3 \pm 3.0 \%$ in the treatment period $\left(F_{1,19}=5.06, P=0.04\right)$. Treatment and veterinary clinic did not influence the percentage of cows that died or were euthanized.

\section{DISCUSSION}

Even though the prevalence index of reliability tests often had high values, most of the observers reached substantial or excellent agreement (Appendix Table A2). This indicates that severe conditions (e.g., severe lameness) were recognized quite consistently by the observers, and the kappa values were only occasionally low.

In this study, just over half the cows were in the marketing system for more than $3 \mathrm{~d}$, even though most $(80 \%)$ were slaughtered in an abattoir located less than $300 \mathrm{~km}$ from most of the farms and from the large livestock markets in the lower Fraser Valley region of British Columbia (Figure 1). Primary reasons for delays to slaughter, as reported by others, are lack of infrastructure and low slaughter capacity of available plants (Stojkov et al., 2018; Edwards-Callaway et al., 2019). The abattoir located in Washington State that slaughtered the majority of the cows in the current study also slaughtered many cull dairy cows from nearby states, and this likely contributed to delays. In contrast, cows sent to the local abattoirs were slaughtered faster, but these plants slaughtered only a small percentage of the cows, and 1 plant discontinued slaughtering cattle during the study. More local facilities for slaughtering cull dairy cows are needed to service areas with a large concentration of dairy farms; the local dairy industry is encouraged to identify the steps needed to build the necessary infrastructure.

\section{Changes in Condition from Farm to Abattoir}

While dairy cows were on the culling list (i.e., from the decision to cull until the decision to ship) and in the marketing system (i.e., from farm to abattoir) their BCS declined. Compared with body weight, which can vary due to frame size and gut content, BCS is more representative of body fat reserves (Wright and Russel, 1984) and is a useful indicator of animals' nutritional status (Burkholder, 2000). Extremely low body condition is usually linked with poor health (e.g., milk fever, lameness) or malnutrition (reviewed by Roche et al., 2009). In this study, cull dairy cows were exposed to multiple factors (e.g., transport, stress, handling) that likely contributed to a reduction in body condition, probably reflecting poor welfare. In particular, the higher odds of being thin $(\mathrm{BCS} \leq 2)$ on arrival at abattoirs likely reflected limited access to feed and water while animals were in the marketing system. For example, at livestock markets cattle in presale pens were not given feed and water, but those kept in holding pens before being transported to an abattoir were provided with water and sometimes low-quality feed (e.g., hay). Moreover, the transport, repeated loading and offloading, and mixing with unfamiliar animals likely reduced feed intake and caused stress that can initiate mobilization of body reserves (Ferguson and Warner, 2008; Warren et al., 2010b; Marques et al., 2012).

Surprisingly, cows observed at livestock markets had lower (i.e., better) locomotion scores than when observed at the farm of origin. This may reflect a reduction in gait abnormality caused by distraction (Gentle, 2001). The novel environment of livestock markets, where cows are held individually in a noisy sales ring close to unfamiliar handlers, could shift animals' attention away from the pain of lameness (Gentle, 2001). In addition, the sawdust flooring of the sales ring is softer 
than the concrete floors where the on-farm scoring was conducted; this may have improved stride length and symmetry of gait (reviewed by Cook and Nordlund, 2009).

In this study, severe lameness did not increase in cows between farm and abattoir, although short-duration transport has been reported to increase lameness scores in cull dairy cows (Dahl-Pedersen et al., 2018). The lack of effect in our study might be due to use of the merged locomotion scale that distinguished only severe lameness. In addition, the infrastructure at the abattoirs often prevented observers from evaluating 4 full strides, and some plants had rubber flooring on the unloading track that could improve locomotion (reviewed by Cook and Nordlund, 2009). Moreover, at slaughter plants as at auctions, the new surroundings could have distracted animals' attention from pain (Gentle, 2001).

The occurrence of acute milk accumulation and udder inflammation increased dramatically by the time cows reached the abattoirs, presumably because most cows were in the marketing system for more than $3 \mathrm{~d}$ without being milked. This indicates a serious animal welfare problem. Udder inflammation, regardless of severity, is considered painful (Leslie and Petersson-Wolfe, 2012; Fitzpatrick et al., 2013), and even subclinical mastitis has been reported to increase pain sensitivity in cows (Peters et al., 2015). Acute milk accumulation increases intramammary pressure, resulting in tissue damage, discomfort, pain, and stress, as indicated by increased levels of fecal cortisol metabolites (Bertulat et al., 2013; reviewed by Zobel et al., 2015). Even cows with low milk production (around 10 to $15 \mathrm{~kg} / \mathrm{d}$ ) have increased udder pressure and fecal cortisol metabolites that peak at d 2 after cessation of milking (Tucker et al., 2009; Bertulat et al., 2013).

Overall fitness for transport, as assessed by a combination of body condition, lameness, and udder condition scores, declined while cows were on the culling list (i.e., until farmers reached the decision to ship). Reaching this decision is influenced by multiple factors, and, in this study, increased milk demand in BC during 2017 may have resulted in delayed culling decisions, as described in expanding herds (Weigel et al., 2003; Hadley et al., 2006). Moreover, for many cows (n = 313), fitness for transport was lower when they arrived at the abattoirs than when they left the farm, probably because most of the cows spent more than $3 \mathrm{~d}$ in the marketing system, where many lost body condition and developed udder engorgement or inflammation (Appendix Table A3).

Fitness for transport also declined with increasing parity and was lower for cows culled during early stages of lactation (Table 4). In particular, cows in the first stage of lactation had higher odds of being thin, likely because many recently calved cows experience metabolic or infectious diseases that can reduce feed intake and body condition (LeBlanc, 2010). Compared with primiparous cows, older cows ( $>$ 3rd parity) had higher odds of losing body condition. Similarly, an onfarm study found that multiparous cows experience more intense body condition loss and slower recovery (Gallo et al., 1996). Cows with higher parity also had higher odds of developing severe lameness by the time they arrived at abattoirs; other on-farm studies have also reported that high-parity cows had greater risk of lameness and lower chances of recovery (Reader et al., 2011; Solano et al., 2015). The odds of developing udder edema were highest at the first stage of lactation but were maintained throughout the other stages of lactation and increased with parity, as described in other on-farm studies of mastitis (Barkema et al., 1998; Olde Riekerink et al., 2008).

\section{Effect of Providing Information}

Culling decisions did not appear to be influenced by providing information to farmers but seem affected by other factors. The temporal analysis suggested that 1 likely factor was the increased demand for milk in BC during 2017. Specifically, the demand for milk increased during the first months of the study (May to Nov., the baseline period) but not during most of the treatment period (Dec. to Mar.). In the Canadian supply-management system, farmers are required to achieve any increases in production set by the provincial Milk Marketing Board to avoid penalties. This may well have influenced farmers to retain cows in the herd during the baseline period to increase milk production, such that shipping was delayed until some animals were in poor condition ("involuntary culling"; Weigel et al., 2003; Fetrow et al., 2006; Hadley et al., 2006). Hence, when shipped under these market conditions, a higher percentage of cows were thin (perhaps due to health problems) or had poor fitness for transport when removed from farms. Moreover, the health condition of some cows that remained on farms might have deteriorated to such a degree that cows became unfit for transport and had to be euthanized, or some might have died on-farm. This suggests that increased milk demand, as occurred in BC during 2017, can have an important, albeit unintended, effect on animal welfare.

The literature gives little evidence of how increased demand for milk influences culling decisions and the welfare of dairy cows. However, some studies from the United States have described the effect of herd expansion on culling (Weigel et al., 2003; Fetrow et al., 2006; Hadley et al., 2006). For example, fewer animals may be culled in the first few years after herd expansion (Had- 
ley et al., 2006), and expanding herds practice more involuntary culling of high-producing cows compared with the pre-expansion period (Weigel et al., 2003). This trend was also more obvious in larger herds $(>150$ cows) and herds with higher average milk production (>11,340 kg; Weigel et al., 2003). As noted by Fetrow et al. (2006), management to achieve the short-term goal of expanding the herd involves retaining less-favorable cows and reducing the culling rate. Once herd expansion is complete and the cash flow is stabilized, farmers replace undesirable cows with better cows, and normal culling resumes (Fetrow et al., 2006).

In this study the clients of some veterinary clinics made better culling decisions than did clients of other clinics. This may indicate that some farm managers use different criteria when making culling decisions (Beaudeau et al., 1996), or that some veterinary clinics give advice on culling or are more involved in culling decisions. Future studies should explore the scope for greater veterinary involvement in on-farm culling decisions.

\section{CONCLUSIONS}

In this study, many cows removed from dairy farms were in the marketing system for more than $3 \mathrm{~d}$ before being slaughtered. During this time the cows' body condition deteriorated, and many animals developed signs of udder engorgement or inflammation and reduced fitness for transport. Unfortunately, providing such information to producers had no clear effect on subsequent culling decisions. However, an increased demand for milk appeared to lead to delayed culling that resulted in a higher percentage of cows shipped with poor fitness for transport, and in more on-farm deaths and euthanasia. Fitness-for-transport guidelines for cull dairy cows need to consider body condition and udder health (i.e., drying-off) in light of the long delays to slaughter that can occur. Moreover, the Canadian supply-management system needs procedures that would allow increasing milk demand without causing undue delays in culling.

\section{ACKNOWLEDGMENTS}

This project was completed with support from many organizations and individuals. We thank all participating dairy farmers from the Fraser Valley, BC, Abattoir Association and the abattoirs that kindly gave us access to their facilities, BC Food Safety and Inspection Branch (Victoria, Canada), Canadian Food Inspection Agency (CFIA, Ottawa, ON)-Meat Hygiene Division, the United States Department of Agriculture-Food Safety and Inspection Service (USDA-FSIS, Washing- ton, DC), BC Mountain Livestock Markets Association (Kamloops, Canada), Livestock Markets Association of Canada (Virden, MB), the auction markets that kindly cooperated, and the local veterinary clinics, especially Agwest Veterinary Group Ltd. (Abbotsford, BC, Canada), that helped us recruit participants and assisted in many ways. Participants are not mentioned by name in order to preserve confidentiality, but we express heartfelt gratitude to them all. We are especially grateful to our colleagues in the BC Ministry of Agriculture (Abbotsford) for their support and cooperation, particularly Jane Pritchard, Terri Giacomazzi, Tom Droppo, and Brian Radke, and to Erin Cuthbert, who helped in data collection. We are grateful to Geneviève Bénard (CFIA), who assisted in establishing productive relations with CFIA and USDA inspectors. We thank the staff and students at the University of British Columbia's Dairy Education and Research Centre (Agassiz, Canada), especially Nelson Dinn for providing valuable information about on-farm culling decisions and Devon Wilson (UBC Animal Welfare Program, Vancouver), who helped in data collection and carried out the information meetings with farmers. We appreciate the continuous statistical support from Biljana Jonoska Stojkova (UBC Applied Statistics and Data Science Group). Funding for this project was provided by the BC Ministry of Agriculture (Victoria) through Growing Forward 2, a federal-provincial-territorial initiative, and by Loblaw Companies Limited (Brampton, ON, Canada). General support for the University of British Columbia Animal Welfare Program is provided by Canada's Natural Sciences and Engineering Research Council Industrial Research Chair Program (Ottawa, ON, Canada) with industry contributions from Dairy Farmers of Canada (Ottawa, ON, Canada), British Columbia Dairy Association (Burnaby, BC, Canada), Westgen Endowment Fund (Milner, BC, Canada), Intervet Canada Corporation (Kirkland, QC, Canada), Zoetis (Kirkland, QC, Canada), Novus International Inc. (Oakville, ON, Canada), BC Cattle Industry Development Fund (Kamloops, BC, Canada), Alberta Milk (Edmonton, AB, Canada), Valacta (St Anne-deBellevue, QC, Canada), and CanWest DHI (Guelph, ON, Canada). The authors do not have conflicts of interest.

\section{REFERENCES}

Ahola, J. K., H. A. Foster, D. L. VanOverbeke, K. S. Jensen, R. L. Wilson, J. B. Glaze Jr., T. E. Fife, C. W. Gray, S. A. Nash, R. R. Panting, and N. R. Rimbey. 2011. Survey of quality defects in market beef and dairy cows and bulls sold through livestock auction markets in the Western United States: I. Incidence rates. J. Anim. Sci. 89:1474-1483. https://doi.org/10.2527/jas.2010-3170.

Barkema, H. W., Y. H. Schukken, T. J. G. M. Lam, M. L. Beiboer, H. Wilmink, G. Benedictus, and A. Brand. 1998. Incidence of clinical 
mastitis in dairy herds grouped in three categories by bulk milk somatic cell counts. J. Dairy Sci. 81:411-419. https://doi.org/10 .3168/jds.S0022-0302(98)75591-2.

Beaudeau, F., H. Seegers, V. Ducrocq, C. Fourichon, and N. Bareille. 2000. Effect of health disorders on culling in dairy cows: A review and a critical discussion. Ann. Zootech. 49:293-311. https://doi .org/10.1051/animres:2000102.

Beaudeau, F., J. D. van der Ploeg, B. Boileau, H. Seegers, and J. P. T. M. Noordhuizen. 1996. Relationships between culling criteria in dairy herds and farmers' management styles. Prev. Vet. Med. 25:327-342. https://doi.org/10.1016/0167-5877(95)00509-9.

Bertulat, S., C. Fischer-Tenhagen, V. Suthar, E. Möstl, N. Isaka, and W. Heuwieser. 2013. Measurement of fecal glucocorticoid metabolites and evaluation of udder characteristics to estimate stress after sudden dry-off in dairy cows with different milk yields. J. Dairy Sci. 96:3774-3787. https://doi.org/10.3168/jds.2012-6425.

Burkholder, W. J. 2000. Use of body condition scores in clinical assessment of the provision of optimal nutrition. J. Am. Vet. Med. Assoc. 217:650-654. https://doi.org/10.2460/javma.2000.217.650.

CARC. 2001. Recommended code of practice for the care and handling of farm animals: Transportation. Canadian Agri-Food Research Council (CARC). Accessed Sep. 9, 2019. http://www.nfacc.ca/ pdfs/codes/transport_code_of_practice.pdf.

CDIC. 2019. Breed improvement and genetic evaluation: Culling and replacement rates in dairy herds in Canada. Canadian Dairy Information Center (CDIC). Accessed Apr. 12, 2019. http://www .dairyinfo.gc.ca/index_e.php?s1=dff-fcil\&s2 $=$ mrr-pcle\&s3 $=$ cr-tr.

CFIA. 2019. Transportation of Animals Program: Compromised Animals Policy. Canadian Food Inspection Agency (CFIA). Accessed Apr. 10, 2019. http://www.inspection.gc.ca/animals/terrestrial -animals/humane-transport/compromised-animals-policy/eng/ $1360016317589 / 1360016435110$.

Cook, N. B., and K. V. Nordlund. 2009. The influence of the environment on dairy cow behavior, claw health and herd lameness dynamics. Vet. J. 179:360-369. https://doi.org/10.1016/j.tvjl.2007 .09 .016 .

Dahl-Pedersen, K., M. S. Herskin, H. Houe, and P. T. Thomsen. 2018. Risk factors for deterioration of the clinical condition of cull dairy cows during transport to slaughter. Front. Vet. Sci. 5:297. https:/ /doi.org/10.3389/fvets.2018.00297.

DFC-PLC. 2017. ProAction Reference Manual \& Workbook Integrated for Food Safety, Animal Care, and Traceability Modules. Dairy Farmers of Canada-Producteurs Laitier du Canada (DFC-PLC), Ottawa, ON, Canada.

Edmonson, A. J., I. J. Lean, L. D. Weaver, T. Farver, and G. Webster. 1989. A body condition-scoring chart for Holstein dairy cows. J. Dairy Sci. 72:68-78. https://doi.org/10.3168/jds.S0022 -0302(89)79081-0.

Edwards-Callaway, L. N., J. Walker, and C. B. Tucker. 2019. Culling decisions and dairy cattle welfare during transport to slaughter in the United States. Front. Vet. Sci. 5:343. https://doi.org/10.3389/ fvets.2018.00343.

Evans, N. J., R. D. Murray, and S. D. Carter. 2016. Bovine digital dermatitis: Current concepts from laboratory to farm. Vet. J. 211:3-13. https://doi.org/10.1016/j.tvjl.2015.10.028.

Ferguson, D. M., and R. D. Warner. 2008. Have we underestimated the impact of pre-slaughter stress on meat quality in ruminants? Meat Sci. 80:12-19. https://doi.org/10.1016/j.meatsci.2008.05.004.

Ferguson, J. D., D. T. Galligan, and N. Thomsen. 1994. Principal descriptors of body condition score in Holstein cows. J. Dairy Sci. 77:2695-2703. https://doi.org/10.3168/jds.S0022-0302(94)77212 $-\mathrm{X}$.

Fetrow, J., K. V. Nordlund, and H. D. Norman. 2006. Culling, nomenclature, definitions, and recommendations. J. Dairy Sci. 89:18961905. https://doi.org/10.3168/jds.S0022-0302(06)72257-3.

Fitzpatrick, C. E., N. Chapinal, C. S. Petersson-Wolfe, T. J. DeVries, D. F. Kelton, T. F. Duffield, and K. E. Leslie. 2013. The effect of meloxicam on pain sensitivity, rumination time, and clinical signs in dairy cows with endotoxin-induced clinical mastitis. J. Dairy Sci. 96:2847-2856. https://doi.org/10.3168/jds.2012-5855.
Flower, F. C., and D. M. Weary. 2006. Effect of hoof pathologies on subjective assessments of dairy cow gait. J. Dairy Sci. 89:139-146. https://doi.org/10.3168/jds.S0022-0302(06)72077-X.

Gallo, L., P. Carnier, M. Cassandro, R. Mantovani, L. Bailoni, B. Contiero, and G. Bittante. 1996. Change in body condition score of Holstein cows as affected by parity and mature equivalent milk yield. J. Dairy Sci. 79:1009-1015. https://doi.org/10.3168/jds .S0022-0302(96)76452-4.

Gentle, M. J. 2001. Attentional shifts alter pain perception in the chicken. Anim. Welf. 10:S187-S194.

González, L. A., K. S. Schwartzkopf-Genswein, M. Bryan, R. Silasi, and F. Brown. 2012a. Benchmarking study of industry practices during commercial long haul transport of cattle in Alberta, Canada. J. Anim. Sci. 90:3606-3617. https://doi.org/10.2527/jas.2011 -4770 .

González, L. A., K. S. Schwartzkopf-Genswein, M. Bryan, R. Silasi, and F. Brown. 2012b. Relationships between transport conditions and welfare outcomes during commercial long haul transport of cattle in North America. J. Anim. Sci. 90:3640-3651. https://doi .org/10.2527/jas.2011-4796.

Hadley, G. L., C. A. Wolf, and S. B. Harsh. 2006. Dairy cattle culling patterns, explanations, and implications. J. Dairy Sci. 89:22862296. https://doi.org/10.3168/jds.S0022-0302(06)72300-1.

Harris, M. K., L. C. Eastwood, C. A. Boykin, A. N. Arnold, K. B. Gehring, D. S. Hale, C. R. Kerth, D. B. Griffin, J. W. Savell, K. E. Belk, D. R. Woerner, D. L. Vanoverbeke, G. G. Mafi, M. M. Pfeiffer, T. B. Schmidt, and R. J. Maddock. 2017. National Beef Quality Audit - 2016: Transportation, mobility, live cattle, and carcass assessments of targeted producer-related characteristics that affect value of market cows and bulls, their carcasses, and associated by-products. Transl. Anim. Sci. 1:570-584. https://doi .org/10.2527/tas2017.0063.

LeBlanc, S. 2010. Monitoring metabolic health of dairy cattle in the transition period. J. Reprod. Dev. 56(Suppl.):S29-S35. https://doi .org/10.1262/jrd.1056S29.

Leslie, K. E., and C. S. Petersson-Wolfe. 2012. Assessment and management of pain in dairy cows with clinical mastitis. Vet. Clin. North Am. Food Anim. Pract. 28:289-305. https://doi.org/10 .1016/j.cvfa.2012.04.002

Marques, R. S., R. F. Cooke, C. L. Francisco, and D. W. Bohnert. 2012. Effects of twenty-four hour transport or twenty-four hour feed and water deprivation on physiologic and performance responses of feeder cattle. J. Anim. Sci. 90:5040-5046. https://doi . org $/ 10.2527 /$ jas. $2012-5425$.

Moorman, A. K. G. T. F. Duffield, M. A. Godkin, D. F. Kelton, J. Rau, and D. B. Haley. 2018. Associations between the general condition of culled dairy cows and selling price at Ontario auction markets. J. Dairy Sci. 101:10580-10588. https://doi.org/10.3168/ jds.2018-14519.

NFACC. 2009. Code of Practice for the Care and Handling of Dairy Cattle. National Farm Animal Care Council (NFACC). Accessed Apr. 10, 2019. https://www.nfacc.ca/pdfs/codes/dairy_code_of _practice.pdf.

Olde Riekerink, R. G. M., H. W. Barkema, D. F. Kelton, and D. T. Scholl. 2008. Incidence rate of clinical mastitis on Canadian dairy farms. J. Dairy Sci. 91:1366-1377. https://doi.org/10.3168/ jds.2007-0757.

Peters, M. D. P., I. D. B. Silveira, and V. Fischer. 2015. Impact of subclinical and clinical mastitis on sensitivity to pain of dairy cows. Animal 9:2024-2028. https://doi.org/10.1017/S1751731115001391.

Reader, J. D., M. J. Green, J. Kaler, S. A. Mason, and L. E. Green. 2011. Effect of mobility score on milk yield and activity in dairy cattle. J. Dairy Sci. 94:5045-5052. https://doi.org/10.3168/jds .2011-4415.

Roche, J. R., N. C. Friggens, J. K. Kay, M. W. Fisher, K. J. Stafford, and D. P. Berry. 2009. Body condition score and its association with dairy cow productivity, health, and welfare. J. Dairy Sci. 92:5769-5801. https://doi.org/10.3168/jds.2009-2431.

Sim, J., and C. C. Wright. 2005. The kappa statistic in reliability studies: Use, interpretation, and sample size requirements. Phys. Ther. 85:257-268. https://doi.org/10.1093/ptj/85.3.257. 
Solano, L., H. W. Barkema, E. A. Pajor, S. Mason, S. J. LeBlanc, J. C. Zaffino Heyerhoff, C. G. R. Nash, D. B. Haley, E. Vasseur, D. Pellerin, J. Rushen, A. M. de Passillé, and K. Orsel. 2015. Prevalence of lameness and associated risk factors in Canadian HolsteinFriesian cows housed in freestall barns. J. Dairy Sci. 98:6978-6991. https://doi.org/10.3168/jds.2015-9652.

Stojkov, J., G. Bowers, M. Draper, T. Duffield, P. Duivenvoorden, M. Groleau, D. Haupstein, R. Peters, J. Pritchard, C. Radom, N. Sillett, W. Skippon, H. Trépanier, and D. Fraser. 2018. Management of cull dairy cows - Consensus of an expert consultation in Canada. J. Dairy Sci. 101:11170-11174. https://doi.org/10.3168/ jds.2018-14919.

Tucker, C. B., S. J. Lacy-Hulbert, and J. R. Webster. 2009. Effect of milking frequency and feeding level before and after dry off on dairy cattle behavior and udder characteristics. J. Dairy Sci. 92:3194-3203. https://doi.org/10.3168/jds.2008-1930.

Van Donkersgoed, J., G. Jewison, S. Bygrove, K. Gillis, D. Malchow, and G. McLeod. 2001. Canadian beef quality audit 1998-99. Can. Vet. J. 42:121-126.

Warren, L. A., I. B. Mandell, and K. G. Bateman. 2010a. An audit of transport conditions and arrival status of slaughter cattle shipped by road at an Ontario processor. Can. J. Anim. Sci. 90:159-167. https://doi.org/10.4141/CJAS09068.

Warren, L. A., I. B. Mandell, and K. G. Bateman. 2010b. Road transport conditions of slaughter cattle: Effects on the prevalence of dark, firm and dry beef. Can. J. Anim. Sci. 90:471-482. https:// doi.org/10.4141/cjas09091.

Weigel, K. A., R. W. Palmer, and D. Z. Caraviello. 2003. Investigation of factors affecting voluntary and involuntary culling in expanding dairy herds in Wisconsin using survival analysis. J. Dairy Sci. 86:1482-1486. https://doi.org/10.3168/jds.S0022-0302(03)73733 $-3$.

Whay, H. R., A. E. Waterman, A. J. Webster, and J. K. O'Brien. 1998. The influence of lesion type on the duration of hyperalgesia associated with hindlimb lameness in dairy cattle. Vet. J. 156:23-29. https://doi.org/10.1016/S1090-0233(98)80058-0.

Wright, I. A., and A. J. F. Russel. 1984. Partition of fat, body composition and body condition score in mature cows. Anim. Prod. 38:23-32. https://doi.org/10.1017/S0003356100041313.

Zobel, G., D. M. Weary, K. E. Leslie, and M. A. G. von Keyserlingk. 2015. Cessation of lactation: Effects on animal welfare. J. Dairy Sci. 98:8263-8277. https://doi.org/10.3168/jds.2015-9617.

\section{ORCIDS}

J. Stojkov $\odot$ https://orcid.org/0000-0002-0806-2391

M. A. G. von Keyserlingk @ https://orcid.org/0000-0002-1427-3152

T. Duffield ๑ https://orcid.org/0000-0001-6035-4669 


\section{APPENDIX}

Table A1. Frequency and percentage distribution of parity of cull dairy cows $(\mathrm{n}=1,110)$ removed from the 20 participating farms; information about parity was missing for 61 cows

\begin{tabular}{lccc}
\hline Parity & Frequency & Percent & $\begin{array}{c}\text { Cumulative } \\
\text { frequency }\end{array}$ \\
\hline 1 & 258 & 23.24 & 258 \\
2 & 268 & 24.14 & 526 \\
3 & 242 & 21.8 & 768 \\
4 & 173 & 15.59 & 941 \\
5 & 99 & 8.92 & 1,040 \\
6 & 47 & 4.23 & 1,087 \\
7 & 13 & 1.17 & 1,100 \\
8 & 6 & 0.54 & 1,106 \\
9 & 3 & 0.27 & 1,109 \\
10 & 1 & 0.09 & 1,110 \\
\hline
\end{tabular}

Table A2. Intra- and interobserver agreement of observers $(\mathrm{n}=9: 1$ primary, 2 auxiliary, and 6 observers at the abattoirs), including range of kappa coefficients, prevalence index (PI), and bias index (BI)

\begin{tabular}{|c|c|c|c|c|}
\hline Observers/agreement & Measure & Kappa & PI & BI \\
\hline \multicolumn{5}{|l|}{ Intraobserver agreement } \\
\hline \multirow[t]{2}{*}{ Primary assessor } & BCS & $0.54-1.00$ & $0.76-0.84$ & $0.00-0.08$ \\
\hline & Lameness & $0.90-1.00$ & $0.15-0.76$ & $0.00-0.05$ \\
\hline \multirow[t]{3}{*}{ Auxiliary assessors } & $\mathrm{BCS}$ & $0.48-1.00$ & $0.89-0.95$ & $0.00-0.05$ \\
\hline & Lameness & $0.69-1.00$ & $0.58-0.91$ & $0.00-0.10$ \\
\hline & Udder condition & $0.92-1.00$ & $0.23-0.78$ & $0.00-0.03$ \\
\hline Abattoir assessors & Udder condition & $0.79-1.00$ & $0.07-0.59$ & $0.00-0.06$ \\
\hline \multicolumn{5}{|l|}{ Interobserver agreement } \\
\hline \multirow[t]{3}{*}{ Primary versus auxiliary assessors } & BCS & $0.47-1.00$ & $0.82-0.94$ & $0.00-0.07$ \\
\hline & Lameness & $0.64-0.89$ & $0.25-0.82$ & $0.03-0.15$ \\
\hline & Udder condition & $0.69-1.00$ & $0.03-0.50$ & $0.00-0.07$ \\
\hline \multirow[t]{2}{*}{ Primary versus abattoir assessors } & BCS & $0.45-0.84$ & $0.68-0.83$ & $0.03-0.18$ \\
\hline & Lameness & $0.52-1.00$ & $0.35-0.85$ & $0.00-0.16$ \\
\hline
\end{tabular}

Table A3. Percentage of cows observed with low body condition (BCS $\leq 2$ ), severe lameness [locomotion score (LS) $\geq 4$ ], poor udder condition (udder condition $\geq 2$ ), and poor fitness for transport (cow that had 1 or more of the following conditions: BCS $\leq 2$, LS $\geq 4$, or udder condition $\geq 2)$, at the 4 points of assessment $(1=$ when placed on culling list, $2=$ when placed on shipping list, $3=$ at auction, $4=$ at abattoir $)$; numbers in parentheses indicate number of animals with the condition as a fraction of the number assessed

\begin{tabular}{|c|c|c|c|c|}
\hline Assessment point & $\begin{array}{c}\text { Low body } \\
\text { condition } \\
{[\% \text { (no./no.)] }}\end{array}$ & $\begin{array}{c}\text { Severe } \\
\text { lameness } \\
{[\% \text { (no./no.) }]}\end{array}$ & $\begin{array}{l}\text { Poor udder } \\
\text { condition } \\
{[\% \text { (no./no.)] }}\end{array}$ & $\begin{array}{l}\text { Poor fitness } \\
\text { for transport } \\
{[\% \text { (no./no.) }]}\end{array}$ \\
\hline Placed on culling list & $9(71 / 815)$ & $10(77 / 808)$ & - & $16(130 / 815)$ \\
\hline At auction & $7(41 / 614)$ & $4(26 / 611)$ & $6(39 / 609)$ & $15(95 / 615)$ \\
\hline At abattoir & $27(139 / 517)$ & $10(38 / 395)$ & $48(229 / 475)$ & $60(313 / 518)$ \\
\hline
\end{tabular}

